\title{
Logistics of an Advanced Therapy Medicinal Product During Covid-19 Pandemic in Italy: Successful Delivery of Mesenchymal Stromal Cells in Dry lce
}

Giuseppe Astori ( $\sim$ giuseppe.astori@aulss8.veneto.it )

Laboratory of Advanced Cellular Therapies, Haematology Unit, Vicenza Hospital, Italy

Martina Bernardi

Laboratory of Advanced Cellular Therapies, Haematology Unit, Vicenza Hospital, Italy.

\section{Angela Bozza}

Laboratory of Advanced Cellular Therapies, Haematology Unit, Vicenza Hospital, Italy.

\section{Daniela Catanzaro}

Laboratory of Advanced Cellular Therapies, Haematology Unit, Vicenza Hospital, Italy.

\section{Katia Chieregato}

Laboratory of Advanced Cellular Therapies, Haematology Unit, Vicenza Hospital, Italy.

\section{Anna Merlo}

Laboratory of Advanced Cellular Therapies, Haematology Unit, Vicenza Hospital, Italy.

\section{Monica Santimaria}

Nuclear Medicine Service, Department of Diagnostics; Vicenza Hospital, Italy

\section{Roberto Barbazza}

Pharmacy Service, Department of Medical Management; A.O.U.I. Ospedale Maggiore; Verona, Italy

\section{Giuseppe Amodeo}

Gastroenterology Unit, Department of Medicine, A.O.U.I. Policlinico G.B. Rossi \& University of Verona;

Verona, Italy

\section{Rachele Ciccocioppo}

Gastroenterology Unit, Department of Medicine, A.O.U.I. Policlinico G.B. Rossi \& University of Verona; Verona, Italy

\section{Francesca Elice}

Haematology Unit, Vicenza Hospital, Italy

\section{Marco Ruggeri}

Haematology Unit, Vicenza Hospital, Italy

\section{Research Article}


Keywords: COVID-19, GvHD, Mesenchymal Stromal Cells, Supply Chain

Posted Date: September 3rd, 2020

DOI: https://doi.org/10.21203/rs.3.rs-69205/v1

License: (c) (1) This work is licensed under a Creative Commons Attribution 4.0 International License. Read Full License

Version of Record: A version of this preprint was published at Journal of Translational Medicine on November 30th, 2020. See the published version at https://doi.org/10.1186/s12967-020-02625-0. 


\section{Abstract}

Background: During the coronavirus disease-2019 (COVID-19) pandemic, Italian hospitals faced the most daunting challenges of their recent history, and only essential therapeutic interventions were feasible. From March to April 2020, the Laboratory of Advanced Cellular Therapies (Vicenza, Italy) received requests to treat a patient with severe COVID-19 and a patient with acute graft-versus-host disease with umbilical cord-derived mesenchymal stromal cells (UC-MSCs). Access to clinics was restricted due to the risk of contagion. Transport of UC-MSCs in liquid nitrogen was unmanageable, leaving shipment in dry ice as the only option.

Methods: We assessed effects of the transition from liquid nitrogen to dry ice on cell viability; apoptosis; phenotype; proliferation; immunomodulation; and clonogenesis; and validated dry ice-based transport of UC-MSCs to clinics.

Results: Our results showed no differences in cell functionality related to the two storage conditions, and demonstrated the preservation of immunomodulatory and clonogenic potentials in dry ice. UC-MSCs were successfully delivered to points-of-care, enabling favourable clinical outcomes.

Conclusions: This experience underscores the flexibility of a public cell factory in its adaptation of the logistics of an advanced therapy medicinal product during a public health crisis. Alternative supply chains should be evaluated for other cell products to guarantee delivery during catastrophes.

\section{Background}

Advanced therapy medicinal products (ATMPs), including stem cells, are usually stored and cryopreserved in liquid nitrogen $\left(\mathrm{LN}_{2}\right)$ and delivered to points-of-care by authorized couriers using dry vapour (dewar) shippers. This enables the direct transport of ATMPs to points-of-care, where they are thawed and infused at the bedside, primarily because hospital pharmacy services do not have access to $\mathrm{LN}_{2}$ freezers. Moreover, vapour-phase shipment requires not only specific logistical resources, but also strict adherence to handling procedures for $\mathrm{LN}_{2}$ supplies by trained personnel(1). During the severe acute respiratory syndrome coronavirus-2 (SARS-CoV-2) pandemic, Italian hospitals faced the most daunting challenges of our recent history. In this context, the capability to provide ATMPs was impeded by the urgent need to prevent viral transmission to trained couriers and other ancillary personnel.

Mesenchymal stromal cells (MSCs) are non-hematopoietic progenitors that can be isolated from several adult and fetal tissues, and can differentiate into three cellular lineages under appropriate stimuli. Their characterization is based upon criteria defined by the International Society for Cell \& Gene Therapies $(2,3)$, which include a common phenotype, even though specific markers have been identified to distinguish MSCs from different sources $(4,5)$. In the last decade, both scientists and clinicians have investigated the potent immunomodulatory effects of MSCs on all immune effector cell subpopulations, $(6,7)$ particularly 
T-cells(8-11). Consequently, MSCs are an attractive therapeutic candidate for autoimmune disorders(12) such as acute graft-versus-host disease (aGvHD), a complication of bone marrow transplantation that carries high morbidity and mortality $(13,14)$. Thus, Dazzi and colleagues demonstrated in an elegant work that MSC death may drive immunosuppression, and that the cytotoxic activity of T lymphocytes and NK cells against MSCs may predict clinical response(15). Notably, when infused intravenously, the vast majority of MSCs are entrapped in the lungs(16), although neither their localization nor their engraftment to the target organ are required for their efficacy. Another condition for which MSCs have been used is severe coronavirus disease-2019 (COVID-19), in which pathogenesis is triggered by a virus-induced exaggerated immune response ("cytokine storm")(17) that causes an acute respiratory distress syndrome (ARDS). Indeed, based on the safety and possible efficacy of MSCs in ARDS trials $(18,19)$, a case series of seven patients suffering from severe COVID-19 pneumonia were treated with single MSC intravenous infusions $\left(1 \times 10^{6}\right.$ cells $\left./ \mathrm{kg}\right)$ at the Beijing YouAn Hospital, and experienced improved clinical outcomes(20). Numerous clinical trials are ongoing worldwide.

During the Italian pandemic (March to April 2020), the Laboratory of Advanced Cellular Therapies (LTCA, Vicenza, Italy) received requests for serial infusions of umbilical cord-derived mesenchymal stromal cells (UC-MSCs) for a patient with COVID-19-related pneumonia and for a patient with severe intestinal aGvHD. At that time, access to clinics and particularly to COVID-19 units by trained $\mathrm{LN}_{2}$ couriers and other ancillary personnel was prohibited due to the high risk of contagion that forced hospitals to execute unprecedented internal reorganizations and restrictive personnel management policies. Transport of UCMSCs to the clinics in LN2 was unmanageable. The need to ensure the continuity of the therapeutic supply chain prompted us to validate the shipment of cell bags in dry ice as the only possible alternative transport strategy. Dry ice is the solid form of carbon dioxide that sublimates at $-78.5^{\circ} \mathrm{C}$ at sea level. The validation process comprised both prospective assessments of the effects of the transition from $\mathrm{LN}_{2}$ to dry ice on cell function and a concurrent validation during delivery to the bedside. Our successful experience underscored the flexibility of a public cell factory to adapt logistics during a public health crisis, and emphasized need to test additional transport methods to guarantee the transport of other cell products to points-of-care.

\section{Methods}

\section{Advanced Therapy Medicinal Product production and cryopreservation}

When used as therapeutic agents, MSCs are classified as "Advanced Therapy Medicinal Products" (ATMPs) according to European regulation no. 1394/2007. Each ATMP must be produced following Good Manufacturing Practice (GMP) rules in facilities authorized by the national regulatory body. Umbilical cords (UCs) for MSC production were collected during caesarean sections. The mothers provided signed informed consent (Ethics Committee act no. 16/18 of February $3^{\text {rd }}, 2018$ ), and their blood was screened according to European Directive 2004/23/EC, for HCV/HBV/HIV1-DNA, anti-HIV 1+2 Ab, anti-HCV Ab, HBsAg and anti-T. pallidum Ab. Briefly, after collection, UCs were immediately submerged in a decontamination solution containing a cocktail of four antibiotics (BASE 128; Alchimia; Padua, Italy). 
Then, in the clean room, UCs were first minced into small fragments, seeded in conventional T-flasks in complete medium containing human-derived platelet lysate (produced by the blood bank of Meyer Hospital; Florence, I) and were incubated at $37^{\circ} \mathrm{C}$ and $5 \% \mathrm{CO}_{2}$. After 7 days, tissue fragments were removed and medium was substituted. After 13 days, adherent cells were detached by using TrypLe Select (Thermo Fischer; Waltham, MA, USA) and re-seeded in complete medium. On Day 19, adherent cells were detached and expanded in HYPERFlask Cell Culture Vessels (Corning; NY, USA) and on Day 26 cells were harvested, counted and collected in CryoMACS freezing bags (Miltenyi Biotec; Bergisch Gladbach, DE) or in cryotubes (Nalgene; Rochester, NY, USA). Cells were finally frozen to $-140^{\circ} \mathrm{C}$ in a cryogenic freezer (Feezal, Air Liquide; Paris, FR) at a cooling rate of $-1^{\circ} \mathrm{C} / \mathrm{min}$ to $-40^{\circ} \mathrm{C}$ followed by a cooling rate of $-5^{\circ} \mathrm{C} / \mathrm{min}$ to $-140^{\circ} \mathrm{C}$, and finally stored in vapour phase $\mathrm{LN}_{2}$. UC-MSCs bags were released after the quality control check that included sterility, mycoplasma, endotoxins, cell count, phenotype, karyotype, cell viability and impurities tests compliant with European Pharmacopeia methods.

\section{In vitro experimental design}

To simulate the conditions to which cells would be exposed during the alternative shipment method, cells stored in $\mathrm{LN}_{2}$ vapour $(\mathrm{n}=3)$ were incubated for $18 \mathrm{~h}$ in dry ice before thawing; as a control, cells stored in $\mathrm{LN}_{2}$ were thawed directly at $37^{\circ} \mathrm{C}$. Analyses of immuno-phenotype; immuno-modulation; population doubling (PD); cell viability, apoptosis; and colony forming unit-fibroblast (CFU-F) potential were performed as described in Figure 1.

\section{Cell viability, apoptosis and population doubling}

To test viability after thawing, cells were harvested and resuspended in trypan blue (Thermo Fischer) at 1:1 ratio ( $v: v)$ in medium solution. The number of viable/dead cells was scored by using a Burker hemocytometer. For apoptosis testing, $2 \times 10^{5}$ cells were harvested after thawing and centrifuged at $400 \mathrm{~g}$ for $6 \mathrm{~min}$ at $8^{\circ} \mathrm{C}$. Cells were then washed with binding buffer and labelled with Annexin V/7aminoactinomycin D (7-AAD) (Thermo Fischer). After dilution with the binding buffer (1:10 v:v), fluorescence of $2 \times 10^{4}$ cells/sample was detected by using a Cytomics FC500 cytometer and analysed by using EXPO32 software (all by Beckman Coulter; Brea, CA, USA). Cell populations were separated into four subsets: viable cells were negative to both Annexin $V$ and 7-AAD fluorescence; cells in early phase of apoptosis were Annexin $\mathrm{V}^{+} / 7-A A D^{-}$; cells in late phase of apoptosis were Annexin $\mathrm{V}^{+} / 7-A A D^{+}$, while the necrotic cells were Annexin $\mathrm{V}^{-} / 7-A A D^{+}$. Cell viability and apoptosis were determined for both transport conditions ( $\left(\mathrm{LN}_{2}\right.$ and dry ice) immediately after thawing (Day 0$)$ and after one week in culture (Day 7$)$. In the last condition, the PD was calculated after 2-5-7 days as follows: $P D=\left(\log _{10} \mathrm{Nt}-\log _{10} \mathrm{NO}\right) / \log _{10}$ 2 , where $\mathrm{Nt}=$ number of counted cells $\mathrm{N} 0=$ number of plated cells $(\mathrm{n}=3)$.

\section{Immunophenotype}

Briefly, $1 \times 10^{5}$ cells were stained with monoclonal anti-human antibodies against CD31-FITC (Clone 5.6E), CD45-ECD (Clone J.33), CD105-PE (Clone 1G2), CD90-FITC (Clone F15-42-1-5), HLA-DR-APC (Clone IMU 
357) and 7-amino actinomycin D (7-AAD) (all by Beckman Coulter) and CD34-PE (Clone 8G12), CD73-PC7 (Clone AD2) (by Beckton Dickinson; Franklin Lakes, NJ, USA). Cells were incubated for 15 minutes at room temperature together with specific antibodies (CD90/CD105/CD45/7AAD; CD31/CD34/CD45/HLADR/CD73). After washing, at least 10,000 events were acquired using a FC500 flow cytometer and analysed using Kaluza software (both by Beckman Coulter).

\section{Immunomodulation}

Thawed peripheral blood mononuclear cells (PBMCs) collected from a single healthy donor were suspended in RPMI 1640 (Sigma-Aldrich; St. Louis, MO, USA) supplemented with 10\% FBS, 2mM Lglutamine, $100 \mathrm{U} / \mathrm{ml}$ penicillin, $0.1 \mathrm{mg} / \mathrm{ml}$ streptomycin (all by Sigma-Aldrich) and rested overnight at $37^{\circ} \mathrm{C}$ in a humidified atmosphere containing $5 \% \mathrm{CO}_{2}$. UC-MSCs were seeded in 96-well flat-bottom plates (Corning) at different densities: $4 \times 10^{4}, 2 \times 10^{4}$ and $1 \times 10^{4}$ cells. To measure cell proliferation, PBMCs were stained with 5 $\mu \mathrm{M}$ 5,6-carboxyfluorescein diacetate succinimidyl ester (CFSE) (CellTrace Cell Proliferation Kit; Invitrogen, Carlsbad, CA, USA) according to manufacturer's instructions. PBMCs were also stimulated with $0.5 \mu \mathrm{g} / \mathrm{ml}$ of anti-CD3 antibody (clone OKT3, Miltenyi Biotec) and 500Ul/ml of recombinant human interleukin-2 (rh-IL-2, Miltenyi Biotec) for six days before measuring the corresponding decrease in CFSE fluorescence by flow cytometry. Stimulated and unstimulated PBMCs seeded alone were used as controls. CFSE-labeled PBMCs $\left(2 \times 10^{5}\right)$ were then seeded on MSCs monolayers to obtain different MSC:PBMC ratios of 1:5, 1:10 and 1:20. Anti-human CD45-ECD antibody was used to assess proliferation on gated CD45 ${ }^{+}$cells. At least 20,000 events were acquired on a Cytomics FC500 cytometer (Beckman Coulter). PBMC proliferation was quantified as the percentage of cells undergoing at least one cell division $(n=3)$.

\section{Colony forming unit-fibroblast assay}

UC-MSC clonogenic potential was evaluated by seeding 200 cells in a $100-\mathrm{mm}$ plate (Corning), in duplicate for each condition, immediately after thawing (Day 0) or after 7 days (Day 7 ) in culture. Cells were incubated at $37^{\circ} \mathrm{C}$ and $5 \% \mathrm{CO}_{2}$ and the medium was changed at Day 7 . After 13 days in culture, cells were washed, fixed with $10 \%$ formaldheyde and stained with $0.1 \%$ Crystal Violet for one hour at room temperature. Only colonies with a minimum of 30 cells were scored $(n=3)$.

\section{Validation of ATMP delivery in dry ice}

Two concomitant validation runs were performed during the transport of the ATMP from the LTCA in Vicenza to the Intensive Care Unit (ICU) of Ospedale Maggiore in Verona (approximately $60 \mathrm{~km}$ distant, corresponding to less than one hour of driving), and from the LTCA to the Haematology Unit (both in Vicenza, approximately 500 meters distant, corresponding to ten minutes of walking). A third run (worst case) was conducted by maintaining the box container at $35^{\circ} \mathrm{C}$ in a hood (Heraeus; Hanau, DE) for 24 hours in order to "challenge" the system. The goal was to validate the box container and packaging instructions; the quantity of dry ice to be loaded; and the maximum allowable transport time. Packaging 
was done in compliance with UN3373 (Biological substance, Category B) in UN1845 Dry Ice, IATA label Class 9. The box, constituted of high-density polystyrene foam $(27.5 \times 25.0 \times 22.5 \mathrm{~cm}$ and $3.5 \mathrm{~cm}$ thick), was loaded with dry ice in pellets $(5 \mathrm{~kg})$. The dry ice parcel-sized shippers comprised the payload area surrounded by an insulation medium, with the product submerged in dry-ice pellets. The box was filled halfway with dry ice and the bag containing the cells was placed horizontally in contact with a datalogger probe (iLog, Escort Scunthorpe, UK). The box was filled to the brim and closed with the lid sealed with tape. The temperature was recorded every $5 \mathrm{~min}$ and the box was delivered at room temperature by using the courier of the Verona Hospital. As acceptance criteria, the change in weight of dry ice at the end of the worst case test could not exceed $10 \%$, and the temperature of the bags could never exceed $-76^{\circ} \mathrm{C}$.

\section{ATMP administration}

The ATMP was supplied as a frozen, sterile, apyrogenic product in bags containing a concentration of 1 to $2 \times 10^{6}$ cells $/ \mathrm{ml}$. Cells were thawed by continuous agitation in sterile conditions by submerging the bag with an overpouch in a water bath at $37^{\circ} \mathrm{C}$. Once thawed, the overpouch was removed and cells were diluted 1:1 (50 ml final) in thawing solution consisting of 38\% saline; $50 \%$ human albumin $20 \% \mathrm{v} / \mathrm{v}(10 \%$ final); and $12 \%$ anticoagulant Citrate Dextrose Solution (Terumo; Rome, I). The bags were connected to infusion sets, delivered immediately to the clinics, and infused intravenously to patients in $30 \mathrm{~min}$. The treatment consisted of two infusions of $1.1 \times 10^{6} \mathrm{UC}-\mathrm{MSCs} / \mathrm{kg}$ body weight one week apart for the COVID19 patient, and three infusions of $1.5 \times 10^{6} \mathrm{UC}-\mathrm{MSC} / \mathrm{kg}$ body weight one week apart for the aGvHD patient.

\section{Statistical analysis}

The two-tailed Student's $t$-test was used to analyse statistical differences between groups. P-values $<0.05$ were considered statistically significant. All experiments were performed in triplicate. Data are expressed as mean \pm standard deviation (SD). All statistical analyses were performed by using GraphPad Prism software (San Diego, CA, USA).

\section{Results}

\section{Cell viability and population doubling rates}

There were no significant differences between cells stored in $\mathrm{LN}_{2}$ and dry ice in cell viability, early/late apoptosis, and necrosis immediately after thawing. Indeed, the percentage of viable cells was $81.2 \pm 4.3$ and $82.5 \pm 6.2$ respectively. Similar results were obtained after one week in culture. PD of cells stored in the two conditions showed no statistical differences (Figure 2).

\section{Immunophenotyping}

UC-MSCs transferred from $\mathrm{LN}_{2}$ or dry ice to $37^{\circ} \mathrm{C}$ did not show significant differences in the expression of tested antigen markers. Antigen expression was $\geq 99 \%$ for CD105, CD90, CD73 and $\leq 2 \%$ for CD45, CD31, 
CD34 and HLA-DR. Viability was $\geq 90 \%$ in both cases (Table 1 ).

Table 1. Analysis of immunophenotype. Antigen expression of UC-MSCs transferred from $\mathrm{LN}_{2}$ to $37^{\circ} \mathrm{C}$ (left) and from dry ice to $37^{\circ} \mathrm{C}$ (right). No significant differences were demonstrated.

\begin{tabular}{|c|c|c|c|c|c|c|c|c|}
\hline & \multicolumn{4}{|c|}{$\mathrm{NL}_{2}$} & \multicolumn{4}{|c|}{ DRY ICE } \\
\hline & BATCH 1 & BATCH 2 & BATCH 3 & MEAN \pm SD & BATCH 1 & BATCH 2 & BATCH 3 & MEAN $\pm S D$ \\
\hline AAD- & 95.5 & 95.2 & 95.3 & $95.3 \pm 0.2$ & 95.4 & 93.1 & 96.6 & $95.0 \pm 1.8$ \\
\hline D105+ & 99.9 & 99.7 & 99.9 & $99.8 \pm 0.1$ & 99.7 & 99.8 & 99.8 & $99.8 \pm 0.1$ \\
\hline D90+ & 99.7 & 99.7 & 99.8 & $99.7 \pm 0.1$ & 99.8 & 99.7 & 99.6 & $99.7 \pm 0.1$ \\
\hline D73+ & 100.0 & 100.0 & 100.0 & $100.0 \pm 0.0$ & 100.0 & 100.0 & 100.0 & $100.0 \leq 0.0$ \\
\hline D45+ & $\leq 2$ & $\leq 2$ & $\leq 2$ & $\leq 2$ & $\leq 2$ & $\leq 2$ & $\leq 2$ & $\leq 2$ \\
\hline D31+ & $\leq 2$ & $\leq 2$ & $\leq 2$ & $\leq 2$ & $\leq 2$ & $\leq 2$ & $\leq 2$ & $\leq 2$ \\
\hline D34+ & $\leq 2$ & $\leq 2$ & $\leq 2$ & $\leq 2$ & $\leq 2$ & $\leq 2$ & $\leq 2$ & $\leq 2$ \\
\hline HLA DR + & $\leq 2$ & $\leq 2$ & $\leq 2$ & $\leq 2$ & $\leq 2$ & $\leq 2$ & $\leq 2$ & $\leq 2$ \\
\hline
\end{tabular}

\section{Immunomodulation}

The preservation of immunomodulatory activity after thawing is fundamental to assure the in vitro potency of cells and their clinical efficacy. UC-MSCs stored in dry ice for $18 \mathrm{~h}$ before thawing maintained similar antiproliferative activity $v s$. activated PBMCs in comparison to UC-MSCs thawed directly from $\mathrm{LN}_{2}$. Ratio-dependent decrease of PBMC proliferation was maintained in both storage conditions (Figure 3).

\section{CFU-F}

Thawed UC-MSCs maintained their ability to form colonies in culture. Clonogenesis remained identical in both storage conditions (Figure 4).

\section{Validation of ATMP transport in dry ice}

During ATMP delivery, the temperature of cells always remained below $-78^{\circ} \mathrm{C}$ (range from -80.0 to -79.0 ) as confirmed by datalogger records (data not shown). During the "worst case" test, the transport box maintained a stable temperature, even during a 24-h exposure to an external temperature of $35^{\circ} \mathrm{C}$. Dry ice weight loss was limited (30\%) (Table 2).

Table 2. Results of ATMP transport validation in dry ice. Two concurrent and one prospective runs were performed. The temperature of the ATMP always remained below $-76^{\circ} \mathrm{C}$. The maximum delivery time was $24 \mathrm{~h}$. 


\begin{tabular}{|l|c|c|c|c|c|}
\hline DELIVERY DATE & $\begin{array}{c}\text { Temperature } \\
\text { (external) }\end{array}$ & $\begin{array}{c}\text { Delivery } \\
\text { time }\end{array}$ & $\begin{array}{c}\text { Temperature } \\
\text { (start) }\end{array}$ & $\begin{array}{c}\text { Temperature } \\
\text { (arrival) }\end{array}$ & $\begin{array}{c}\text { Dry ice } \\
\text { weight loss }\end{array}$ \\
\hline 07.04 .2020 & $15{ }^{\circ} \mathrm{C}$ & $2 \mathrm{~h} 25 \mathrm{~min}$ & $-86.1{ }^{\circ} \mathrm{C}$ & $-79.1{ }^{\circ} \mathrm{C}$ & $2 \%$ \\
\hline 14.04 .2020 & $20{ }^{\circ} \mathrm{C}$ & $1 \mathrm{~h} 35 \mathrm{~min}$ & $-80.3{ }^{\circ} \mathrm{C}$ & $-78.9{ }^{\circ} \mathrm{C}$ & $1 \%$ \\
\hline 05.05 .2020 & $35{ }^{\circ} \mathrm{C}$ & $24 \mathrm{~h}$ & $-80.6{ }^{\circ} \mathrm{C}$ & $-80.3{ }^{\circ} \mathrm{C}$ & $30 \%$ \\
\hline
\end{tabular}

\section{Advanced Therapy Medicinal Product administration}

We treated a patient with respiratory failure due to COVID-19 pneumonia admitted to the ICU of the Ospedale Maggiore (Verona, Italy) and a patient with grade IV steroid-refractory intestinal aGvHD admitted to the Haematology Unit of the San Bortolo Hospital (Vicenza, Italy) with serial intravenous infusions of UC-MSCs under the Hospital Exemption rule (art. 28 of the Regulation (EC) No. 1394/2007). The dosage of UC-MSCs for each infusion was administered using 2 or 3 bags according to the patient's body weight. During the administration of the content of the first bag, the other bag/s were kept in dry ice. In the absence infusion-related side effects, they were thawed immediately after the completion of the previous bag. No immediate or late adverse events were observed during the four weeks of follow-up in both cases. Moreover, the COVID-19 patient exhibited improved values of numerous laboratory parameters, including biomarkers of inflammation (C-reactive protein from 389 to $24 \mathrm{mg} / \mathrm{L}$; normal value: $<5$ ); renal function (creatinine from 2.27 to $0.56 \mathrm{mg} / \mathrm{dL}$; normal value: 0,59-1,29); coagulation (D-dimer from 3.83 to $0.82 \mathrm{mg} / \mathrm{mL}$; normal value: $<0,25)$; respiratory function $\left(\mathrm{PaO}_{2} / \mathrm{FiO}_{2}\right.$ from 86 to 234; normal value: $>300$ ); and lymphopenia (from 0.6 to $1.48 \times 10^{9} / \mathrm{L}$; normal value: $1,2-4.0$ ) following UC-MSC treatment (Day 10) (Ciccocioppo et al., submitted for publication).

The aGVHD patient experienced clinical improvement, with decreased frequency and volume of diarrhoea, reductions of steroid and analgesic dosages; and improvement of cytopenia (one month after the first UCMSC infusion, leukocyte count increased from $1.4 \times 10^{9} / \mathrm{L}$ to $3.8 \times 10^{9} / \mathrm{L}$, and platelet count rose from $25 \times 10^{9} / \mathrm{L}$ to $75 \times 10^{9} / \mathrm{L}$ ). This experience underscores the preservation of both the safety and efficacy of a dry ice-shipped cellular product.

\section{Discussion}

The pharmaceutical supply chain of ATMPs faces multiple logistic hurdles compared with conventional drug product transport. Although ATMPs can be shipped as either fresh or cryopreserved products, the possibility that minimal temperature changes may reduce cell potency and safety introduces logistical challenges. Biochemical processes are usually temperature-dependent; even at a range between $-20^{\circ} \mathrm{C}$ and $-80^{\circ} \mathrm{C}$, biochemical reactions still occur that result in the accumulation of cytotoxic intermediate compounds such as free radicals, anaerobic metabolism by-products, and waste products that cannot be removed due to the suppression of cellular salvage pathways(21). Consequently, for successful long-term storage, cells must be frozen to temperatures below the glass transition of the cell cryprotectant mixture (approximately $-120^{\circ} \mathrm{C}$ ) so that no mobile water fraction persists in stored samples(1). This is primarily 
why cells should be stored in $\mathrm{LN}_{2}$ in the long term. Consequently, clinical-grade ATMPs are usually delivered in $\mathrm{LN}_{2}$ in dry shippers, in which liquid is entrapped in an absorbent material. However, $\mathrm{LN}_{2}$ is classified as a hazardous gas due to the risk of suffocation. $\mathrm{LN}_{2}$ volume expands 695 times during vaporization, and has no warning properties such as odour or colour. $\mathrm{LN}_{2}$ vapours can rapidly freeze skin tissue and ocular fluids, resulting in cold burns, frostbite, and permanent eye injury, even upon brief exposures. If a sufficient quantity is vaporized and the fraction of inhaled oxygen decreases below $19.5 \%$, there is a risk of hypoxia that may cause unconsciousness or death in extreme cases(22). To prevent asphyxiation, dry shippers should be loaded by trained personnel, and once received at clinics should be manipulated in dedicated rooms.

Historically, cell line shipments to labs have been conducted in dry ice in insulated boxes at approximately $-80^{\circ} \mathrm{C}$. Thermal transport boxes maintain temperatures for time durations related to the quality of the insulation and the quantity of loaded dry ice. Although dry ice is not classified as a hazardous material, prolonged exposures can cause severe skin burns. Because it sublimates into large volumes of carbon dioxide gas that could pose a risk of hypercapnia, thermal boxes containing dry ice should be manipulated in a ventilated environment. Major advantages of dry ice are that it is safer than $\mathrm{LN}_{2}$, and that disposable thermal boxes are used. This is not the case for dry shippers; therefore, the shipment in $\mathrm{LN}_{2}$ must be performed by a dedicated qualified company.

The advent of the chimeric antigen receptor T-cell (CAR)-T era has placed pharmaceutical companies in a global competition. To facilitate commercial-scale production, "Big Pharma” have centralized CAR-T cell manufacturing in large facilities that are often distant from points-of-care. Although this logistic choice has some advantages, the COVID-19 pandemic has highlighted several systemic weaknesses. Border closures and logistical difficulties that confound patient care and the management of ATMPs have forced clinicians to substantially revise CAR-T therapeutic programs(23). This pandemic is teaching us that the production and delivery strategies of cell therapy products should be planned proactively to ensure therapeutic continuity even in the case of further closures of national borders.

In April 2020, during the epidemic peak of COVID-19 in Italy, our laboratory faced the challenge of delivering cryopreserved cell product for therapeutic use in a hospital located far from the production site. At that time, transport of UC-MSCs to the clinic in $\mathrm{LN}_{2}$ was unmanageable. The only alternative was the transport of the ATMP in dry ice. We had no data regarding the potential effects that cell transitions from $\mathrm{LN}_{2}$ to dry ice and then to $37^{\circ} \mathrm{C}$ could have on cell efficacy and safety. The literature concerning the effects of temperature fluctuations of frozen product during sample transfer from $\mathrm{LN}_{2}$ to dry ice was limited(24-27), so we conducted an internal validation process. Chabot et al. showed that warming of UCMSCs from $\mathrm{LN}_{2}$ to approximately $-80^{\circ} \mathrm{C}$ does not have a major impact on MSCs, while internal vial temperatures higher than $-40^{\circ} \mathrm{C}$ significantly impair their antiproliferative effects $v s$. T-cells, and degrade membranous and cytoskeletal integrity(24). Furthermore, the consequences of thermal variations during cell storage have been the object of several studies conducted with frozen PBMCs(25) and placentalderived MSCs(26). In these experiments, designed to simulate events in busy bio-repositories, cells were 
exposed to multiple temperature cycles between $\mathrm{LN}_{2}$ gas phase and temperatures as high as $-60^{\circ} \mathrm{C}$. As expected, reductions of both recovery rate and functionality were detectable compared to stable gas phase storage, however, only when the number of cycles exceeded 20 and/or the peak temperature was higher than $-100^{\circ} \mathrm{C}$, thus indicating that cell damage develops only after several temperature transition cycles. Recently, Mareschi et al. compared the post-thawing viability of cytokine-induced killer cells stored in dry ice for 24 or $48 \mathrm{~h}$ or in $\mathrm{LN}_{2}$ vapours(27). Because cell viability between the two groups was comparable (acceptance criteria was 15\%), the authors concluded that these cells could be shipped safely in dry ice(27).

Under Good Clinical Practice regulations, shipping conditions must also be validated to ensure that the temperature of the product is kept constant during transportation, and that the quantity of refrigerant is sufficient. We have validated the shipping conditions in dry ice from a GMP facility to points-of-care, showing that when using a shipping box containing $5 \mathrm{~kg}$ of dry ice, its weight loss was limited (30\%) while maintained in very unfavourable conditions at $35^{\circ} \mathrm{C}$ for $24 \mathrm{~h}$. Consequently, the choice of in vitro potency assays should take several factors into consideration. First, the trypan blue exclusion text based on membrane integrity is frequently used for the evaluation of post-thaw cell viability, However, this test has several limitations because membrane fluidity that is present immediately after cryopreservation may lead to false-positive or false-negative results. This phenomenon is described as "cryopreservationinduced delayed-onset cell death"(28). It is therefore essential to select potency assays that verify longterm cell functionality. In addition to immediate testing for cell viability; apoptotic rate; and phenotype; we also evaluated cell proliferation; immunomodulation; and clonogenic capacity. Our results allowed us to conclude that in vitro there are no significant differences between the cells transferred from $L_{2} N_{2}$ to $37^{\circ} \mathrm{C}$ water bath and those transferred from $\mathrm{LN}_{2}$ to dry ice and then to $37^{\circ} \mathrm{C}$ water bath in cell viability; apoptosis; phenotype; immunomodulation; and PD. The CFU-F assay has been used historically to evaluate the efficiency with which UC-MSCs form colonies, and it remains a fundamental assay to ascertain the quality of cell preparations. In summary, our data allow us to conclude that there are no differences between the cells stored in $\mathrm{LN}_{2}$ and those kept in dry ice for $18 \mathrm{~h}$. Moreover, in the absence of established laboratory parameters to confirm the clinical efficacy of UC-MSCs in COVID-related pneumonia and aGVHD, we have reported favourable clinical outcomes of the two treated patients. Nonetheless, this experience may be considered a preliminary confirmation of the clinical safety and efficacy of this ATMP delivered by a novel shipping method. Conclusive clinical data on the efficacy and safety of dry ice shipped UC-MSCs in other diseases should be obtained in controlled clinical trials.

\section{Conclusions}

In conclusion, UC-MSCs may be shipped safely in dry ice for a limited time duration without causing functional impairment. However, it should be emphasized that different cell types could react differently to a given cryopreservation protocol. Differences in physical and biological characteristics such as

Page $11 / 18$ 
membrane permeability and surface-to-volume ratio could produce varying responses to cryopreservation processes, leading to differences in viability after subsequent thawing(29). Therefore, it is necessary to optimise the cryopreservation, transportation, and thawing protocols for specific cell types of interest. This experience also underscores the fundamental role of a public GMP facility in proximity to points-ofcare, not only to reduce transit distances, but primarily for the flexibility to react quickly in critical situations, such as the restrictions imposed during the COVID-19 lockdown.

\section{Abbreviations}

ATMPs: Advanced Therapy Medicinal Products; $\mathrm{LN}_{2}$ :liquid nitrogen; SARS-CoV-2: severe acute respiratory syndrome coronavirus-2; MSCs: mesenchymal stromal cells; aGVHD: acute graft-versus-host disease; COVID-19: coronavirus disease-2019; ARDS: acute respiratory distress syndrome; LTCA: Laboratory of Advanced Cellular Therapies; UC-MSCs: umbilical cord-derived mesenchymal stromal cells; CFU-F: colony forming unit-fibroblast; UCs: umbilical cords; GMP: Good Manufacturing Practice; 7-AAD: 7-

aminoactinomycin D; CFSE: 5,6-carboxyfluorescein diacetate succinimidyl ester; ICU: Intensive Care Unit; SD standard deviation.

\section{Declarations}

\section{Ethics approval and consent to participate}

This study was approved by the "Comitato Etico per le Sperimentazioni Cliniche della Provincia di Vicenza" (act no. 16/18 of February $3^{\text {rd }}, 2018$ ). The mothers provided signed informed consent to participate.

\section{Consent for publication}

NA

\section{Availability of data and materials}

The dataset used and/or analysed during the current study are available from the corresponding author on reasonable request.

\section{Competing interests}

The authors declare that they have no competing interests.

\section{Funding}

This work was partially supported by Associazione Vicentina Leucemie e Linfomi (AViLL), Associazione Italiana Leucemie (AIL).

\section{Authors' contributions}


Study design, data analysis and interpretation, manuscript writing and full responsible for UC-MSC product release, GA; UC-MSC production, data collection and analysis, MB, AB, DC; UC-MSC quality control, data collection and analysis, $\mathrm{KC}, \mathrm{AM}$; regulatory support, critical reading of the paper, MS; UCMSC logistic management, RB; clinical data collection and analysis, GAM; UC-MSC administration, clinical data collection and analysis, manuscript writing, RC, FE; financial support, critical reading of the paper, data collection and analysis, MR.

\section{Acknowledgements}

We are grateful to all the mothers for the kind donations of umbilical cords. We are also indebted with Dr. Paolo Lucio Tumaini, Guido Bianchini, and the nurses of the Obstetrics and Gynecology unit of the Arzignano Hospital (Vicenza, Italy) for the collection of the umbilical cords.

We thank Drs. Francesco Fiorin, Chiara Lievore, Cinzia Tagliaferri, and all the staff of the blood bank of the Vicenza Hospital for umbilical cord procurement and screening.

We thank Drs. Anna Montaldi and Paola Celli of the medical genetics service of the Vicenza Hospital for their advice.

Thank to Dr. Franco Bambi and his group at the Cell Factory "A. Meyer," University Children's Hospital, (Florence, Italy) for advice on optimization of freezing-thawing protocols.

We are also indebted to Prof. Michael Matthay, Associate Director of Critical Care Medicine, University of California at San Francisco, USA for his valuable advice during the initial stages of the pandemic in Italy.

\section{References}

1. Massie I, Selden C, Hodgson H, Fuller B. Storage temperatures for cold-chain delivery in cell therapy: a study of alginate-encapsulated liver cell spheroids stored at -80 degrees $\mathrm{c}$ or -170 degrees $\mathrm{c}$ for up to 1 year. Tissue Eng Part C Methods. 2013;19(3):189-95.

2. Pittenger MF, Mackay AM, Beck SC, Jaiswal RK, Douglas R, Mosca JD, et al. Multilineage Potential of Adult Human Mesenchymal Stem Cells. Science. 1999;284(5411):143-7.

3. Dominici M, Le Blanc K, Mueller I, Slaper-Cortenbach I, Marini F, Krause D, et al. Minimal criteria for defining multipotent mesenchymal stromal cells. The International Society for Cellular Therapy position statement. Cytotherapy. 2006;8(4):315-7.

4. Amati E, Perbellini O, Rotta G, Bernardi M, Chieregato K, Sella S, et al. High-throughput immunophenotypic characterization of bone marrow- and cord blood-derived mesenchymal stromal cells reveals common and differentially expressed markers: identification of angiotensin-converting enzyme (CD143) as a marker differentially expressed between adult and perinatal tissue sources. Stem Cell Research \& Therapy. 2018;9:10. 
5. Barilani M, Banfi F, Sironi S, Ragni E, Guillaumin S, Polveraccio F, et al. Low-affinity Nerve Growth Factor Receptor (CD271) Heterogeneous Expression in Adult and Fetal Mesenchymal Stromal Cells. Scientific Reports. 2018;8:9321.

6. Krampera M, Glennie S, Dyson J, Scott D, Laylor R, Simpson E, et al. Bone marrow mesenchymal stem cells inhibit the response of naive and memory antigen-specific $T$ cells to their cognate peptide. Blood. 2003;101(9):3722-9.

7. Glennie S, Soeiro I, Dyson PJ, Lam EW, Dazzi F. Bone marrow mesenchymal stem cells induce division arrest anergy of activated T cells. Blood. 2005;105(7):2821-7.

8. Di Nicola M, Carlo-Stella C, Magni M, Milanesi M, Longoni PD, Matteucci P, et al. Human bone marrow stromal cells suppress T-lymphocyte proliferation induced by cellular or nonspecific mitogenic stimuli. Blood. 2002;99(10):3838-43.

9. Krampera M, Glennie S, Dyson J, Scott D, Laylor R, Simpson E, et al. Bone marrow mesenchymal stem cells inhibit the response of naive and memory antigen-specific T cells to their cognate peptide. Blood. 2003;101(9):3722-9.

10. Le Blanc K, Frassoni F, Ball L, Locatelli F, Roelofs H, Lewis I, et al. Mesenchymal stem cells for treatment of steroid-resistant, severe, acute graft-versus-host disease: a phase II study. Lancet. 2008;371(9624):1579-86.

11. Ciccocioppo R, Bernardo ME, Sgarella A, Maccario R, Avanzini MA, Ubezio C, et al. Autologous bone marrow-derived mesenchymal stromal cells in the treatment of fistulising Crohn's disease. Gut. 2011;60(6):788-98.

12. Ciccocioppo R, Corazza GR. Mesenchymal stem cells for fistulising Crohn's disease. The Lancet. 2016;388(10051):1251-2.

13. Introna M, Rambaldi A. Mesenchymal stromal cells for prevention and treatment of graft-versus-host disease: successes and hurdles. Current Opinion in Organ Transplantation. 2015;20(1):72-8.

14. Fisher SA, Cutler A, Doree C, Brunskill SJ, Stanworth SJ, Navarrete C, et al. Mesenchymal stromal cells as treatment or prophylaxis for acute or chronic graft-versus-host disease in haematopoietic stem cell transplant (HSCT) recipients with a haematological condition. Cochrane Database Syst Rev. 2019;1:CD009768.

15. Galleu A, Riffo-Vasquez Y, Trento C, Lomas C, Dolcetti L, Cheung TS, et al. Apoptosis in mesenchymal stromal cells induces in vivo recipient-mediated immunomodulation. Science Translational Medicine. 2017;9(416).

16. Lee RH, Pulin AA, Seo MJ, Kota DJ, Ylostalo J, Larson BL, et al. Intravenous hMSCs Improve Myocardial Infarction in Mice because Cells Embolized in Lung Are Activated to Secrete the Antiinflammatory Protein TSG-6. Cell Stem Cell. 2009;5(1):54-63.

17. Mehta P, McAuley DF, Brown M, Sanchez E, Tattersall RS, Manson JJ, et al. COVID-19: consider cytokine storm syndromes and immunosuppression. Lancet. 2020;395(10229):1033-4.

18. Matthay MA, Calfee CS, Zhuo H, Thompson BT, Wilson JG, Levitt JE, et al. Treatment with allogeneic mesenchymal stromal cells for moderate to severe acute respiratory distress syndrome (START 
study): a randomised phase 2a safety trial. Lancet Respir Med. 2019;7(2):154-62.

19. Huppert LA, Liu KD, Matthay MA. Therapeutic potential of mesenchymal stromal cells in the treatment of ARDS. Transfusion. 2019;59(S1):869-75.

20. Leng Z, Zhu R, Hou W, Feng Y, Yang Y, Han Q, et al. Transplantation of ACE2(-) Mesenchymal Stem Cells Improves the Outcome of Patients with COVID-19 Pneumonia. Aging Dis. 2020;11(2):216-28.

21. Baust JM, Campbell LH, Harbell JW. Best practices for cryopreserving, thawing, recovering, and assessing cells. In Vitro Cell Dev Biol Anim. 2017;53(10):855-71.

22. Kim DH, Lee HJ. Evaporated liquid nitrogen-induced asphyxia: a case report. J Korean Med Sci. 2008;23(1):163-5.

23. Bachanova V, Bishop MR, Dahi P, Dholaria B, Grupp SA, Hayes-Lattin B, et al. Chimeric Antigen Receptor T Cell Therapy During the COVID-19 Pandemic. Biol Blood Marrow Transplant. 2020;26(7):1239-46.

24. Chabot D, Tremblay T, Pare I, Bazin R, Loubaki L. Transient warming events occurring after freezing impairs umbilical cord-derived mesenchymal stromal cells functionality. Cytotherapy. 2017;19(8):978-89.

25. Angel S, von Briesen H, Oh YJ, Baller MK, Zimmermann H, Germann A. Toward Optimal Cryopreservation and Storage for Achievement of High Cell Recovery and Maintenance of Cell Viability and T Cell Functionality. Biopreserv Biobank. 2016;14(6):539-47.

26. Pogozhykh D, Pogozhykh O, Prokopyuk V, Kuleshova L, Goltsev A, Blasczyk R, et al. Influence of temperature fluctuations during cryopreservation on vital parameters, differentiation potential, and transgene expression of placental multipotent stromal cells. Stem Cell Res Ther. 2017;8(1):66.

27. Mareschi K, Adamini A, Castiglia S, Rustichelli D, Castello L, Mandese A, et al. Cytokine-Induced Killer (CIK) Cells, In Vitro Expanded under Good Manufacturing Process (GMP) Conditions, Remain Stable over Time after Cryopreservation. Pharmaceuticals (Basel). 2020;13(5).

28. Baust JM, Vogel MJ, Van Buskirk R, Baust JG. A molecular basis of cryopreservation failure and its modulation to improve cell survival. Cell Transplant. 2001;10(7):561-71.

29. Hunt CJ. Technical Considerations in the Freezing, Low-Temperature Storage and Thawing of Stem Cells for Cellular Therapies. Transfus Med Hemother. 2019;46(3):134-50.

\section{Figures}




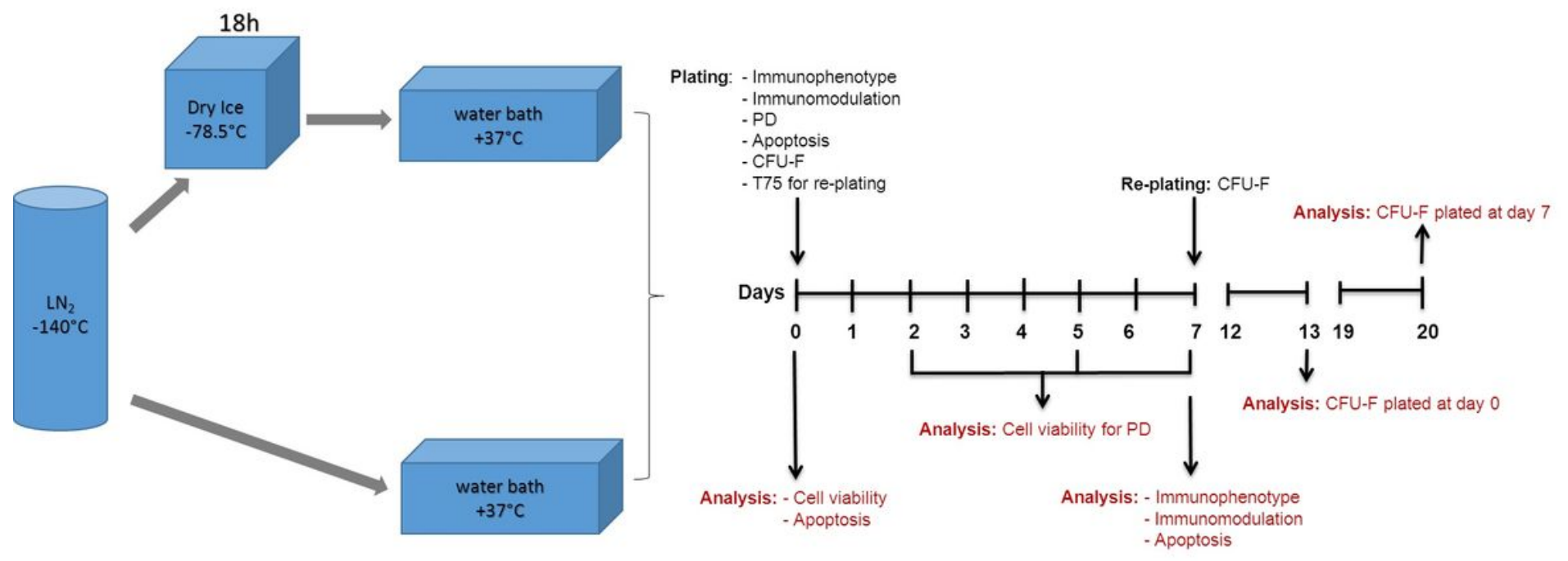

Figure 1

Experimental design. To simulate the different shipment modalities, cells stored in LN2 vapour were thawed directly at $37^{\circ} \mathrm{C}$ or after incubation for $18 \mathrm{~h}$ in dry ice. Cell viability and apoptosis were determined immediately after thawing. Immunophenotype, immunomodulation, and apoptosis were analysed after one week in culture. Population doubling was determined by counting cells at days $0,2,5$ and 7 . CFU-F potential was determined on cells plated immediately after thawing or plated after one week in culture $(n=3)$.

A

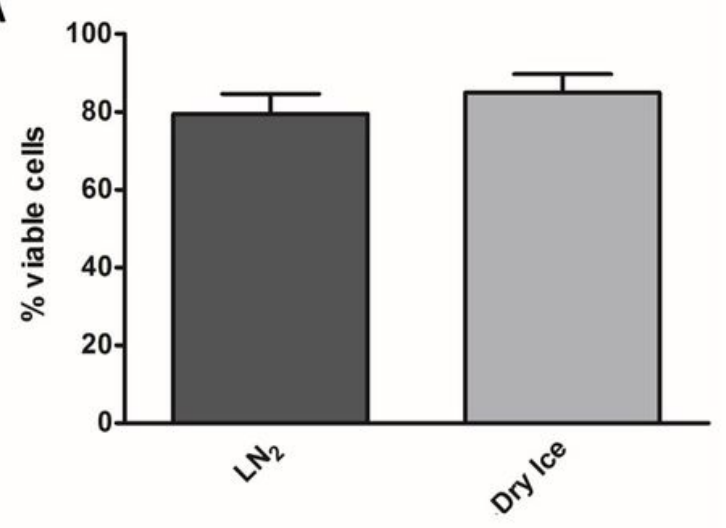

B

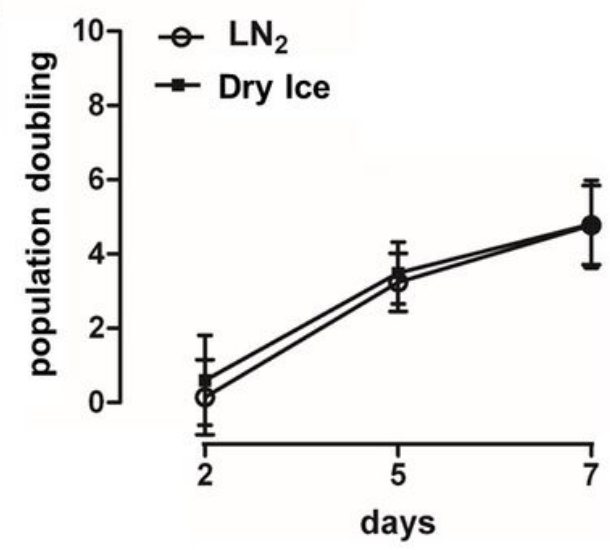

C $\mathrm{LN}_{2}$
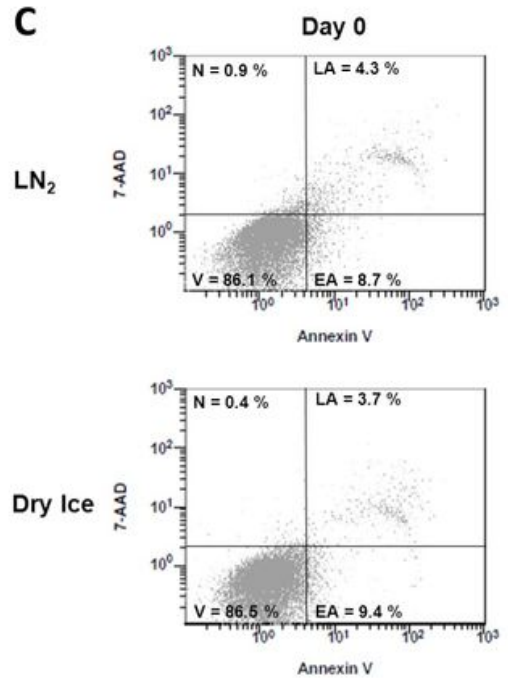
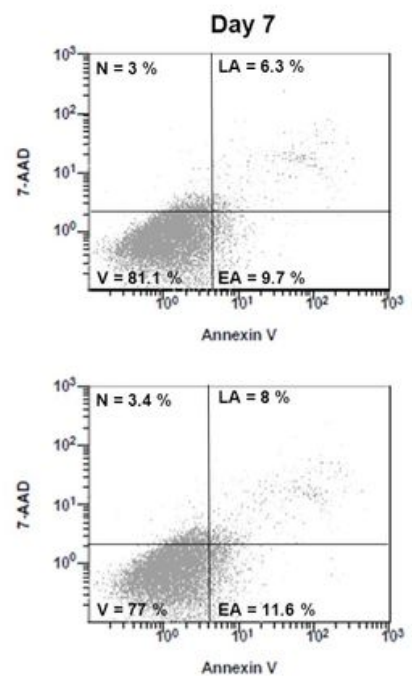

\begin{tabular}{|c|c|c|c|c|}
\cline { 2 - 5 } \multicolumn{1}{c|}{} & \multicolumn{2}{c|}{ Day 0 } & \multicolumn{2}{c|}{ Day 7 } \\
\cline { 2 - 5 } \multicolumn{1}{c|}{} & LN $_{\mathbf{2}}$ & Dry Ice & LN $_{\mathbf{2}}$ & Dry Ice \\
\hline V & $81.2 \pm 4.34$ & $82.5 \pm 6.21$ & $77.5 \pm 6.20$ & $75.0 \pm 9.47$ \\
\hline EA & $9.12 \pm 1.36$ & $8.95 \pm 5.75$ & $9.62 \pm 3.35$ & $9.00 \pm 4.36$ \\
\hline LA & $7.75 \pm 2.94$ & $6.90 \pm 2.97$ & $9.77 \pm 5.07$ & $12.0 \pm 8.27$ \\
\hline N & $1.92 \pm 0.80$ & $0.65 \pm 0.40$ & $3.10 \pm 2.24$ & $4.00 \pm 4.63$ \\
\hline
\end{tabular}

Figure 2 
Analyses of cell viability, apoptosis rates and population doubling. 2A: Histograms of the percentage of viable cells after thawing, measured with trypan blue exclusion assay. 2B: Population doubling (PD) calculated at Days 2, 5 and 7 of culture post-thawing. 2C: Representative cytofluorimetric plots of apoptosis analyses and relative results expressed as percentages. Viability (V), early apoptosis (EA), late apoptosis (LA), and necrosis $(\mathrm{N})$ of cells stored in LN2 and dry ice were analysed immediately after cell thawing (Day 0) or after one week in culture (Day 7). Data are expressed as mean \pm SD of three independent experiments.

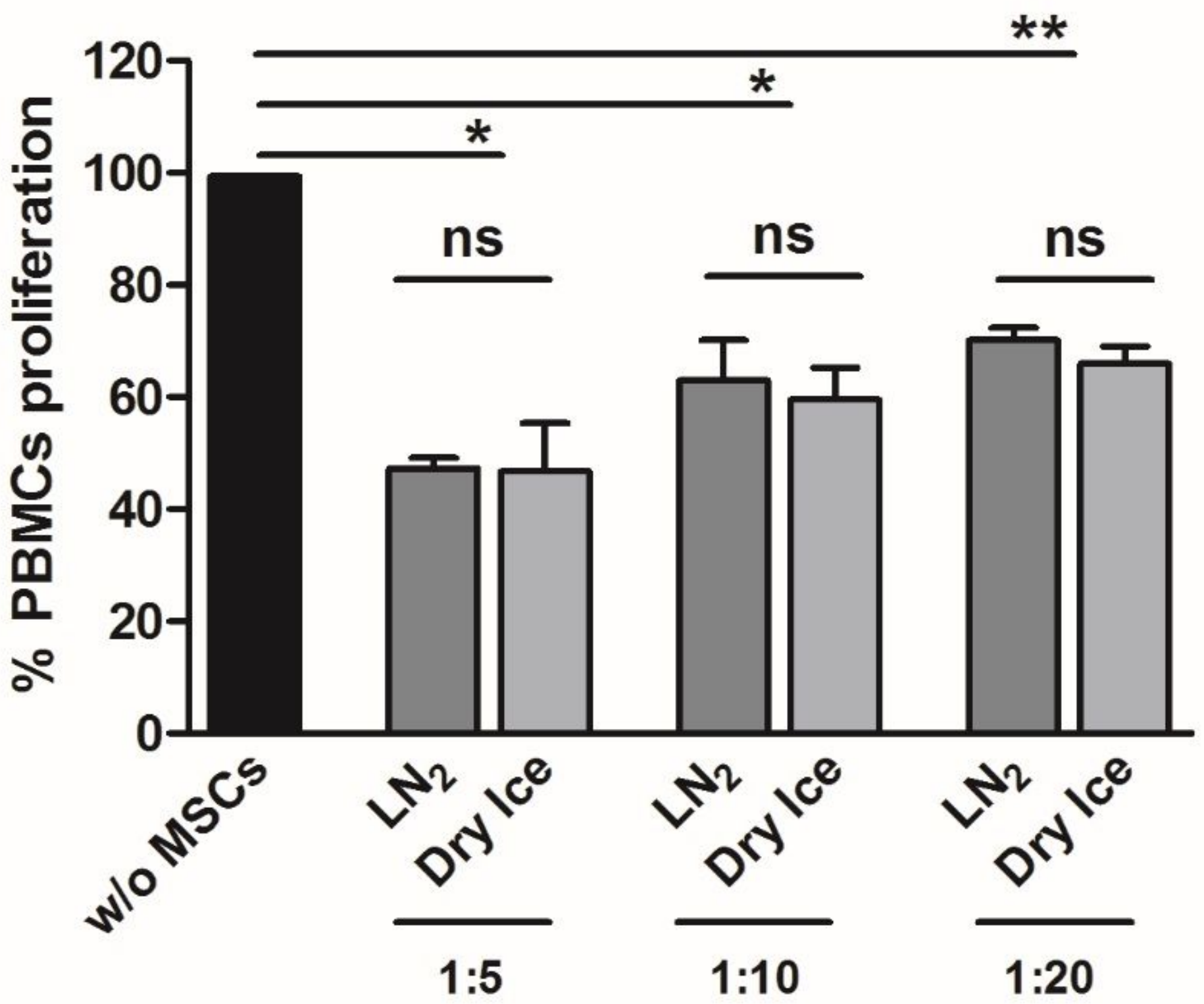

Figure 3

UC-MSCs immunomodulation properties. The anti-proliferative activity of UC-MSCs was analysed by flow cytometry after PBMC labelling with CFSE. Statistical significance is relative to the proliferation of activated lymphocytes in the absence of MSCs $(n=3)\left({ }^{\star} p<0.05 ; * \star p<0.01\right)$. 
A

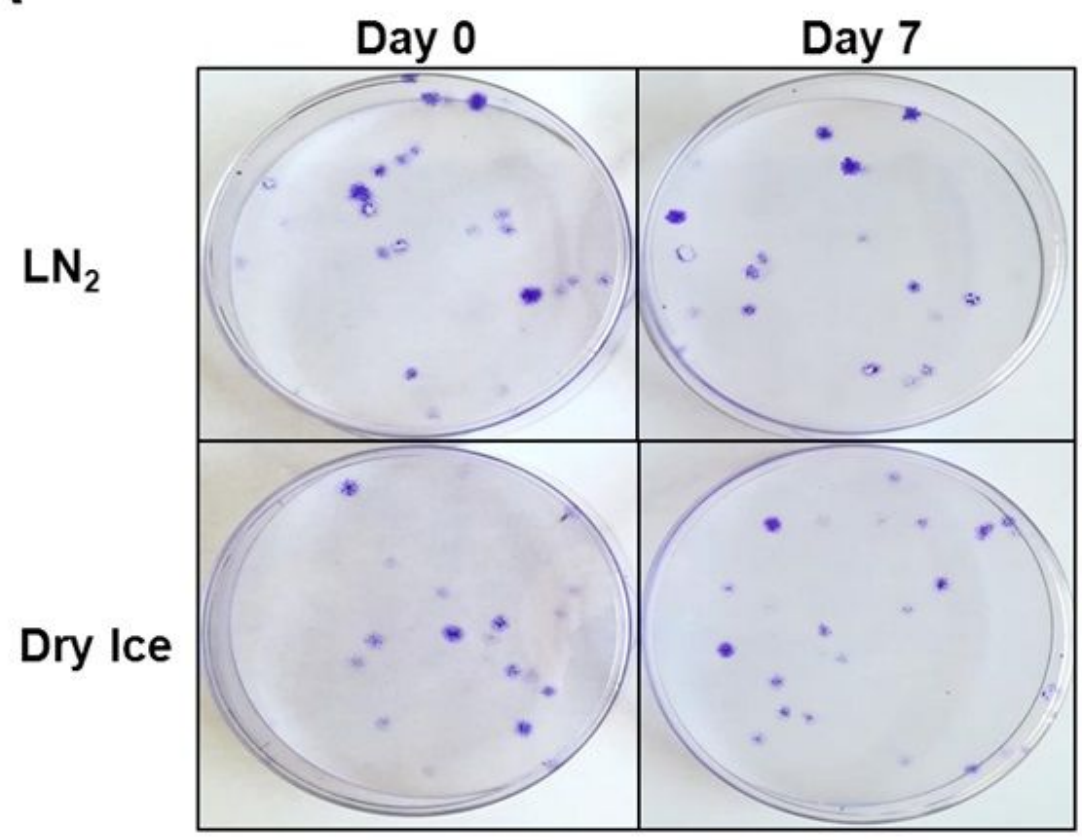

B

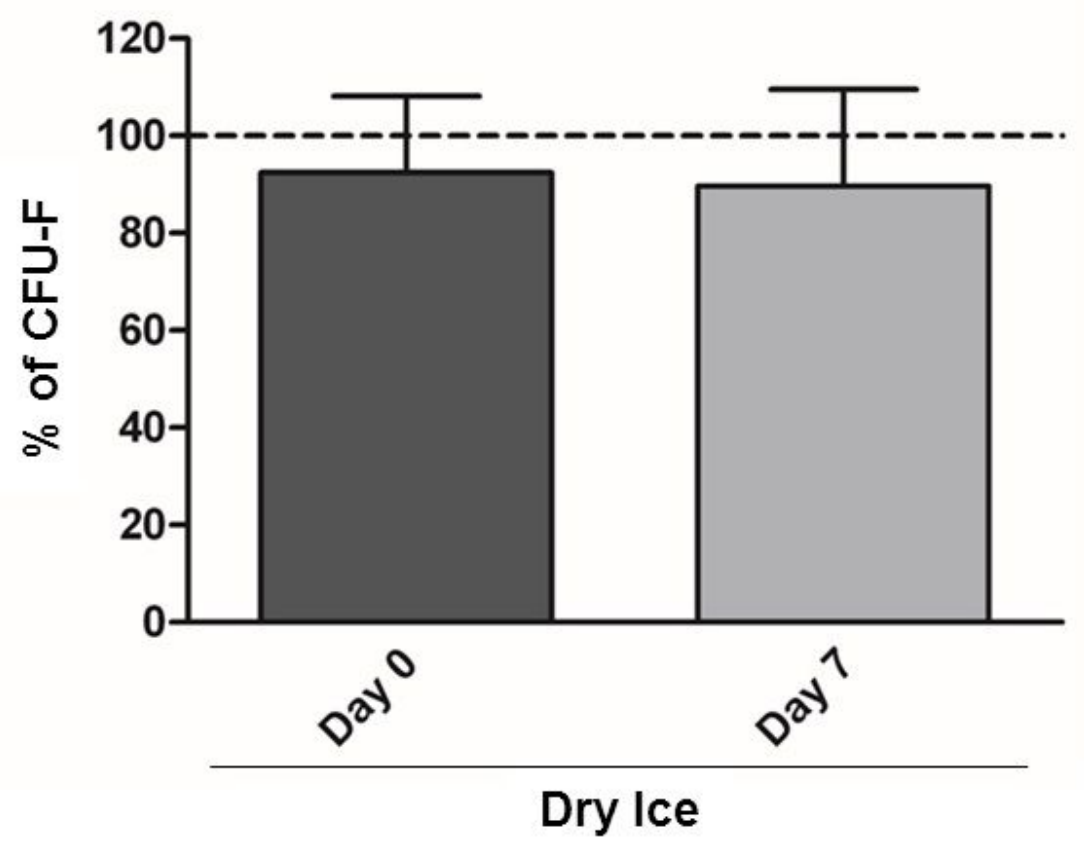

Figure 4

UC-MSC clonogenic potential. 4A: Representative images of CFU-F stained with crystal violet. 4B: Histograms showing the percentage of CFU-F obtained from cells thawed after storage in dry ice compared to control cells, thawed after storage in LN2 (set at 100\%). 